\title{
Downstream Processing of Lentiviral Vectors: Releasing Bottlenecks
}

\author{
Vanessa Bandeira, Cristina Peixoto, Ana F. Rodrigues,, ${ }^{1,2}$ Pedro E. Cruz,, ${ }^{1 *}$ Paula M. Alves,,2 \\ Ana S. Coroadinha, ${ }^{1,2}$ and Manuel J. T. Carrondo ${ }^{1,3}$
}

\begin{abstract}
Lentiviral vectors (LVs) hold great potential as gene delivery vehicles. However, the manufacturing and purification of these vectors still present major challenges, mainly because of the low stability of the virus, essentially due to the fragility of the membrane envelope. The main goal of this work was the establishment of a fast, scalable, and robust downstream protocol for LVs, combining microfiltration, anion-exchange, and ultrafiltration membrane technologies toward maximization of infectious LVs recovery. $\mathrm{CIM}^{\circledR}$ (Convective Interaction Media) monolithic columns with diethylaminoethanol (DEAE) anion exchangers were used for the purification of clarified LV supernatants, allowing infectious vector recoveries of $80 \%$, which is $10 \%$ higher than the values currently reported in the literature. These recoveries, combined with the results obtained after optimization of the remaining downstream purification steps, resulted in overall infectious LV yields of $36 \%$. Moreover, the inclusion of a Benzonase step allowed a removal of approximately $99 \%$ of DNA impurities. The entire downstream processing strategy herein described was conceived based on disposable and easily scalable technologies. Overall, CIM DEAE columns have shown to be a good alternative for the purification of LVs, since they allow faster processing of the viral bulks and enhanced preservation of virus biological activity, consequently, increasing infectious vector recoveries.
\end{abstract}

\section{Introduction}

L ENTIVIRAL VECTORS (LVs) PROVIDE several advantages over other vectors for gene therapy applications, including long-term transgene expression in target cells, low immunogenic potential, and the possibility to transduce dividing and nondividing cells (Naldini et al., 1996a,b; Schambach and Baum, 2008). Because of these advantages, the number of clinical trials using LVs for gene delivery has been increasing worldwide, comparatively to the use of other viral vectors (Gene Therapy Clinical Trials, 2012).

Despite significant progress in LVs manufacturing, including the generation of safer vectors and inducible producer cell lines (Xu et al., 2001; Ikeda et al., 2003), the particles obtained are still unstable, presenting half-lives of 9 to $12 \mathrm{hr}$ at $37^{\circ} \mathrm{C}$ (Higashikawa and Chang, 2001). It is known that retrovirus loss of infectivity can be attributed to the fragility of the lipid membrane layer (affected by cholesterol levels, pseudotyping, temperature, and production medium osmolarity) (Beer et al., 2003; Coroadinha et al., 2006a,b, Carmo et al., 2006) and to the rapid loss of reverse transcriptase activity (Carmo et al., 2008; Carmo et al., 2009). Such drawbacks should also represent major challenges in the development of robust and fast downstream processing (DSP) strategies to produce clinical-grade vector preparations since high-titers (from $10^{7}$ infectious particles (IP)/ml for ex vivo trials up to $10^{9} \mathrm{IP} / \mathrm{ml}$ for in vivo trials) (Segura et al., 2006; Rodrigues et al., 2007b) and high-quality samples are mandatory to achieve the required therapeutic effect. There is, thus, a need to establish an efficient and scalable purification process, allowing rapid processing of large volumes of LVs.

Classical purification protocols make use of several ultracentrifugation steps in order to concentrate the vector preparations. However, centrifugation poses scale limitations, is time consuming, and concentrates impurities that may cause inflammatory or immunogenic reactions or inhibit transduction (Baekelandt et al., 2003; Morenweiser, 2005). Current downstream strategies, based on the integration of membrane and chromatography processes, require a combination of several steps to decrease protein and DNA impurities present in the final vector preparations. Microfiltration is the most popular technique used for clarification of retroviral

\footnotetext{
${ }^{1}$ Instituto de Biologia Experimental e Tecnológica (IBET), 2781-901 Oeiras, Portugal.

${ }^{2}$ Instituto de Tecnologia Química e Biológica, Universidade Nova de Lisboa (ITQB-UNL), 2780-157 Oeiras, Portugal.

${ }^{3}$ Faculdade de Ciências e Tecnologia, Universidade Nova de Lisboa (FCT-UNL), 2829-516 Caparica, Portugal.

*Present address: ECBio S.A, Rua Henrique Paiva Couceiro, 2700-451 Amadora, Portugal.
} 
vector (RV) bulks, and recent studies showed that a novel step filtration system, based on a series of decreasing pore size filters, minimizes the decay of retroviral particles associated with the filtration (Reeves and Cornetta, 2000). Membrane-based methods, such as ultrafiltration/diafiltration (UF/DF), are adequate techniques to concentrate viral stocks. Specifically, tangential flow filtration (TFF) has been applied with success in the concentration and partial purification of LVs, offering scalability, efficiency, and a wide range of processable volumes in short periods of time (Geraerts et al., 2005). The purification of viral bulks can be achieved by chromatographic methods, including heparin affinity, gel filtration, and anion-exchange (AEX) (Transfiguracion et al., 2003; Segura et al., 2005; Rodrigues et al., 2006). AEX chromatography (AEXc) has been a method of choice for LVs purification since negatively charged viral particles bind to the positively charged membranes and can then be eluted with the use of desorption agents or high salt concentrations (Rodrigues et al., 2007a; Schweizer and Merten, 2010). Studies using these chromatographic matrices for the purification of retroviral and lentiviral vectors have shown recoveries of $70 \%$, with host-cell DNA removals reaching 99\% (Slepushkin et al., 2003; Rodrigues et al., 2006; Merten et al., 2011). Small pores on the chromatographic beads can, however, originate low virus-binding capacities and high shear stresses (Rodrigues et al., 2007a) that, adding to the labile nature of most of the viral envelopes used, drastically reduces yields and infectious particle titers. This problem can be circumvented by the use of macroporous supports like monoliths, a relatively recent chromatographic support for purification of nanoparticles like viruses (Gagnon, 2010). $\mathrm{CIM}^{\circledR}$ monoliths combine the advantages of conventional chromatographic columns (separation power, capacity, and sample distribution) with membrane technology (convective mass transport), presenting a matrix composed of methacrylate polymers and highly interconnected flow through pores (Barut et al., 2005; Podgornik and Štrancar, 2005). These structural characteristics have been shown to promote extremely high resolution and binding capacities for viruses, with a low-shear fractionation environment and 10-fold higher operating flow rates compared to particle-based supports (Jungbauer and Hahn, 2008; Gagnon, 2010).

In this study, we present an alternative strategy for the purification of lentiviral vectors, using membrane and chromatographic technologies, including depth-filtration, ultrafiltration/diafiltration, and anion-exchange chromatography (i.e., $\mathrm{CIM}^{\circledR}$ DEAE monolithic columns). The several steps involved in the purification process were optimized, and a reproducible purification platform for LVs downstream processing was established.

\section{Materials and Methods}

\section{Cell line and culture media}

HEK 293T cells (CRL-11268) obtained from the American Type Culture Collection (ATCC) were maintained in Dulbecco's modified Eagle medium (DMEM; Gibco, Life Technologies, Paisley, United Kingdom), supplemented with $10 \%$ (v/v) fetal bovine serum (FBS) (Gibco), in an incubator with humified atmosphere of $7 \% \mathrm{CO}_{2}$ in air at $37^{\circ} \mathrm{C}$. For viral production, cells were grown in DMEM supplemented with $10 \%$ (v/v) FBS without phenol red (Gibco). Cell concentration was assessed by counting cells with the trypan blue exclusion method using a haemocytometer (Gibco) after trypsin cell detachment.

\section{Plasmids}

The HIV-1-derived lentiviral vector particles produced consisted of a transfer vector, pRRLSIN, with an enhanced green fluorescent protein (eGFP), third-generation packaging plasmids pMDLg/pRRE and pRSV-Rev, and the envelope protein plasmid pMD. $2 \mathrm{G}$, encoding the vesicular stomatitis virus envelope glycoprotein (VSV-G). All the plasmids were kindly provided by Didier Trono through Addgene (Cambridge, MA).

\section{Lentiviral vector production}

HEK 293T cells were seeded at a concentration of $5 \times 10^{4}$ cells $/ \mathrm{cm}^{2}$ in HYPERFlask Cell Culture Vessels (Corning Inc., Corning, NY) using $560 \mathrm{ml}$ of DMEM supplemented with $10 \%$ (v/v) FBS. After $24 \mathrm{hr}$, cells were transfected (at $60-80 \%$ of confluence) with the four plasmids referred above, using $5 \mu \mathrm{g}$ of total DNA per $10^{6}$ cells. Transfection conditions were first tested at a small scale; plasmid amount and concentration was optimized so that the concentration of the transfer plasmid exceeds that of the others (3 pRRLSIN : 1.5 pMDLg/pRRE: 1.5 pRSV-Rev: 1 pMD.2G). Plasmids were mixed together in $10 \mathrm{ml}$ of culture media without FBS. Linear $25 \mathrm{kDa}$ polyethylenimine (PEI; Polysciences Inc., Eppelheim, Germany), diluted in sterile water to $1 \mu \mathrm{g} \mu \mathrm{l}^{-1}$, acidified to $\mathrm{pH} 2.0$ with $\mathrm{HCl}$ until dissolution and neutralized to $\mathrm{pH} 7.0$ with $\mathrm{NaOH}$, was used as transfection reagent in a DNA to PEI ratio of 1:3. Transfection complexes (DNA-PEI) were prepared by adding the filtered $(0.22 \mu \mathrm{m})$ DNA mixture to PEI, also previously diluted in $10 \mathrm{ml}$ culture media, without FBS. This mixture was vortexed, incubated for $15 \mathrm{~min}$ at room temperature, and added to $540 \mathrm{ml}$ of culture media. After this, the culture media in the HYPERFlask was exchanged by the new media containing DNA-PEI mixture, and cells were incubated at $37^{\circ} \mathrm{C}$. Forty-eight hr after transfection, LV supernatants were harvested and purified.

\section{Clarification of lentiviral vector supernatants}

To remove cellular debris from the recovered viral supernatants, two methods were compared: batch centrifugation and depth filtration. Batch centrifugation was performed at $10,000 \mathrm{~g}$ for $15 \mathrm{~min}$ at $4^{\circ} \mathrm{C}$. For depth filtration, supernatants were filtered at room temperature using a disposable depth-filter capsule (Sartopore 2; Sartorius Stedim Biotech, Goettingen, Germany) of $0.8+0.45 \mu \mathrm{m}$ pore size and with an effective filtration area of $50 \mathrm{~cm}^{2}$. Clarification was carried out at 50 and $100 \mathrm{ml} \mathrm{min}^{-1}$; the clarified supernatants, collected in sterile containers, were then subjected to AEXc. Before clarification, depth-filters were equilibrated either with $10 \mathrm{~m} M$ Tris buffer $(1 \mathrm{mM} \mathrm{MgCl}$, at $\mathrm{pH}$ 8.0) (Merck, Darmstad, Germany) or with culture media (DMEM, Gibco). 


\section{Anion-exchange chromatography}

For AEXc, the performance of $\mathrm{CIM}^{\circledR}$ DEAE monolithic columns (BIA Separations, Villach, Austria) and Sartobind ${ }^{\circledR}$ D MA75 (Sartorius Stedem Biotech) membrane adsorbers was evaluated. Both matrices were coupled to an ÄKTAexplorer 100 chromatography system (GE Healthcare, Uppsala, Sweden), equipped with UV, conductivity and $\mathrm{pH}$ sensors, and a fraction collector, controlled online with the coupled UNICORN software (all from GE Healthcare). Matrices were equilibrated with $10 \mathrm{mM}$ Tris buffer ( $\mathrm{pH}$ 8.0). After sample loading, the matrices were washed with $10 \mathrm{mM}$ Tris buffer ( $\mathrm{pH}$ 8.0) to remove the nonbinding material. Stepwise elution started with $10 \mathrm{mM}$ Tris buffer ( $\mathrm{pH} 8.0$ ) with $0.1 \mathrm{M} \mathrm{NaCl}$ to release the weakly bonded proteins. Next, elution of the LVs was carried out using $10 \mathrm{mM}$ Tris buffer with $0.65 \mathrm{M} \mathrm{NaCl}$. Finally, in order to regenerate the column and remove stronger bonded impurities from the column, such as DNA, $10 \mathrm{mM}$ Tris buffer with $1 \mathrm{M} \mathrm{NaCl}$ was used. This final step is performed with the aim of regenerating the column and evaluating the column's efficiency in the removal of residual DNA from the viral samples.

Three different elution buffers were evaluated: $10 \mathrm{mM}$ Tris (pH 8.0), phosphate-buffered saline (PBS) (Gibco), and $50 \mathrm{mM}$ 4-(2-hydroxyethyl)-1-piperazine ethanesulfonic acid (HEPES) at pH 7.4 (Sigma-Aldrich, St Louis, MO). The flow

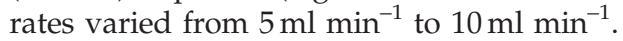

\section{Concentration assays}

For the concentration step, UF/DF techniques were used. Three different systems were tested: Vivaspin polyethersulfone membranes of 100 and $300 \mathrm{kDa}$ molecular weight cut-off (MWCO) and Vivaflow cassettes of $100 \mathrm{kDa}$ MWCO (all from Sartorius). Concentration with Vivaspin membranes was performed by centrifugation at $3,000 \mathrm{~g}$ at $4^{\circ} \mathrm{C}$, in a swing bucket rotor, until the desirable volume was attained. Vivaflow cassettes were previously saturated with $20 \mathrm{ml}(4 \mathrm{~g} / \mathrm{L})$ of human serum albumin (HSA) (Sigma) for approximately $3 \mathrm{~min}$, at a flow rate of $7 \mathrm{ml} \mathrm{min}^{-1}$, in order to prevent unspecific adsorption of the LVs to the membrane. The applied inlet pressure was approximately 1 bar at $150 \mathrm{rpm}$. For Vivaflow systems, a continuous recirculation of the concentrate to the feed was performed until $5 \%$ of total size exclusion chromatography (SEC) column volume was reached.

\section{Polishing and storage}

SEC was performed with a Superdex XK26/60 column (GE Healthcare) with Tris buffer (pH 7.8) in $150 \mathrm{mM} \mathrm{NaCl}$ and with a flow rate of $2 \mathrm{ml} \mathrm{min}^{-1}$. The final LV preparation was recovered, subjected to a sterile microfiltration using $0.22 \mu \mathrm{m}$ Acrodisc Syringe Filters (Pall, Port Washington, NY), aliquoted, and stored at $-85^{\circ} \mathrm{C}$ until further analysis. All the purification steps referred to were performed at $4^{\circ} \mathrm{C}$.

A cryoprotecting formulation of $0.5 \mathrm{M}$ of sucrose (Merck) and $0.6 \mathrm{mg} / \mathrm{ml}$ of HSA was added to the viral samples before freezing to reduce loss of infectious particles. In order to analyze the effect of the addition of these formulations, several aliquots (with an already known infectious titer) were frozen at $-85^{\circ} \mathrm{C}$ with and without this cryoprotecting formulation. After $24 \mathrm{hr}$, samples were thawed on ice and their infectious titer was quantified by the method described in the section "Analysis of viral titers."

\section{Benzonase treatment and DNA impurities}

To digest residual nucleic acids from host producer cells and plasmid DNA present in the LVs bulk, samples from different steps of DSP were incubated with Benzonase endonuclease grade II (Merck), at a concentration of $50 \mathrm{U} / \mathrm{ml}$ for $30 \mathrm{~min}$ at $37^{\circ} \mathrm{C}$.

Total DNA content of the samples from each step of the process (including those incubated with Benzonase) was quantified with Quant-iT PicoGreen dsDNA Assay Kit (Molecular Probes Inc., Eugene, OR), using Modulus Microplate Luminometer (Gentaur, Brussels, Belgium) and standard fluorescent wavelengths (excitation $\sim 480 \mathrm{~nm}$; emission $\sim 520 \mathrm{~nm})$.

\section{Analysis of viral titers}

To determine the infectious titer of the vectors carrying an eGFP reporter gene, $5 \times 10^{4} 293 \mathrm{~T}$ cells $/ \mathrm{cm}^{2}$ were seeded and transduced (at $60-80 \%$ confluence), with serial dilutions of viral suspensions (from each step of the process), in DMEM (Gibco) containing 10\% FBS (v/v) (Gibco) and $8 \mu \mathrm{g} / \mathrm{ml}$ of polybrene (Sigma). Forty-eight hours after transduction, quantification of infectious particles was performed by monitoring the expression of the eGFP reporter gene using CYFlow Space flow cytometer (Partec, Munster, Germany). In order to estimate the stability of the infectious particles in high salt concentrations, samples obtained after AEXc were incubated at $4^{\circ} \mathrm{C}$ in Tris- $\mathrm{HCl}$ with $0.65 \mathrm{M}$ of $\mathrm{NaCl}$ for $30 \mathrm{~min}$. After this period, infectious titer of these samples was quantified and compared to the titer obtained when the same samples were diluted with Tris- $\mathrm{HCl}$ immediately after elution.

P24 capsid protein quantification was performed to estimate the total viral particles present in the LV samples using the Innotest HIV Antigen mAb kit (Innogenetics N.V., Gent, Belgium), following the manufacturer's instructions.

\section{Results}

\section{Downstream processing of lentiviral vectors}

The main objective of this work was to establish a downstream processing protocol for the purification of LVs based on AEXc, aiming at high recoveries of infectious particles and faster processing of the viral bulks with scale-up potential. The general experimental design of the LVs downstream process followed is depicted in Figure 1.

Clarification assays. The first step in a downstream process is the clarification of the viral bulk to remove cells and cellular debris. In this study, the performance of batch centrifugation and disposable depth-filter capsules was compared. For the depth-filters, a flow rate of $50 \mathrm{ml} \mathrm{min} \mathrm{m}^{-1}$ was used after pre-wetting the membranes with Tris buffer. For both methods, recoveries of $70 \%$ were obtained (Table 1 ). The performance of the depth-filter capsules after prewetting the membranes with culture medium (DMEM) or Tris buffer was also analyzed. Comparable recoveries $(71 \pm 4 \%$ vs. $74 \pm 2 \%$, respectively) were obtained. Furthermore, an increase of the loading flow rate from 50 to $100 \mathrm{ml} \mathrm{min}^{-1}$ permitted to 


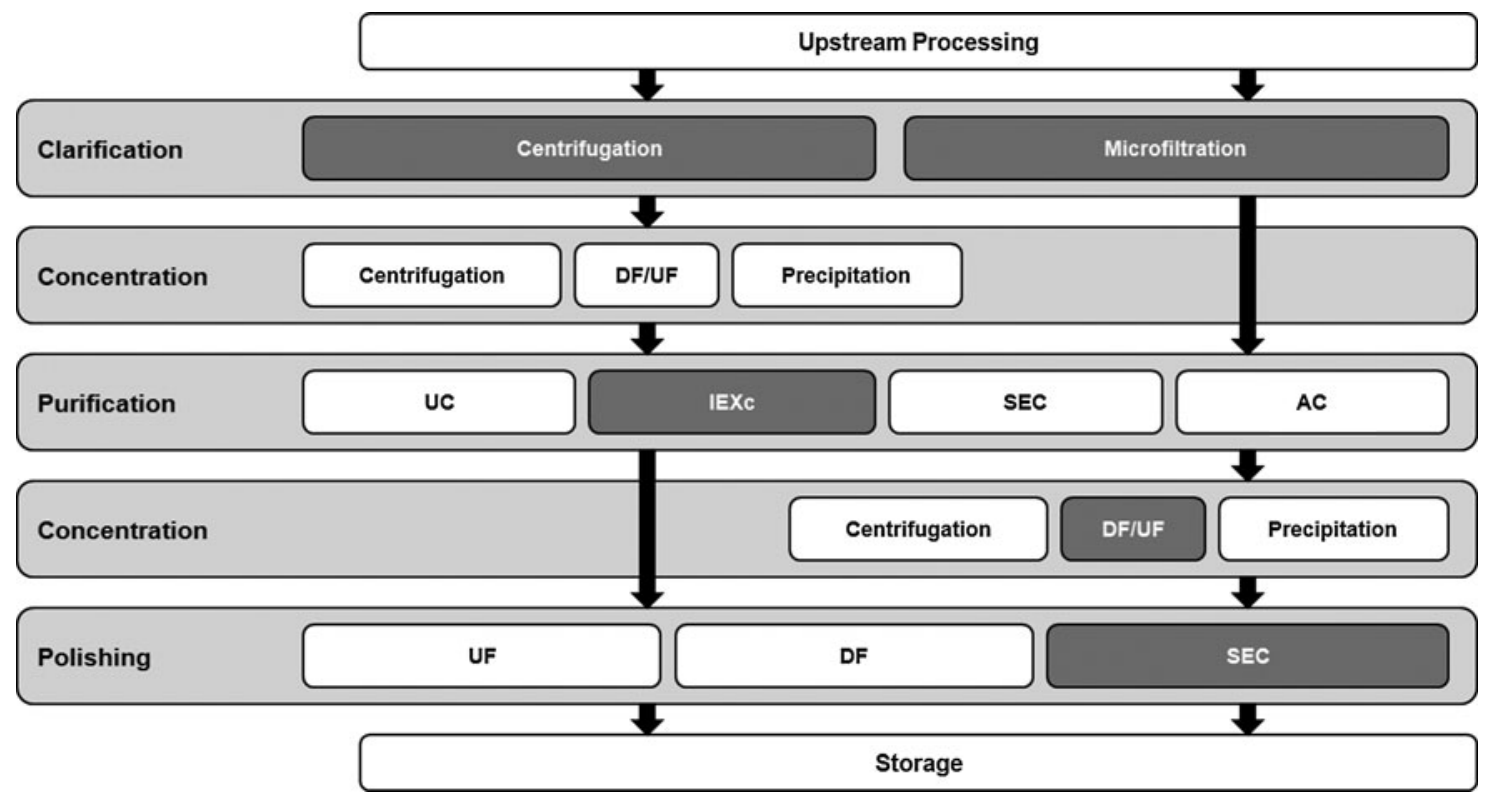

FIG. 1. Overview of the downstream strategies described in the literature for the purification of lentiviral vectors. Boxes in dark gray show the different techniques compared and used in this work. UC, ultracentrifugation; IEC, ion-exchange chromatography (including AEXc, anion-exchange chromatography); SEC, size-exclusion chromatography; AC, affinity chromatography; DF/UF, diafiltration/ultrafiltration.

increase the infectious vector recoveries up to $91 \pm 6 \%$ when depth-filter capsules were used for clarification (Table 1).

Anion-exchange chromatography. After clarification, a purification step to isolate the LVs from proteins and DNA impurities was performed. Two different AEXc-capture matrices were tested: Sartobind ${ }^{\circledR}$ D MA75 and CIM ${ }^{\circledR}$ DEAE monolithic columns, both eluted with Tris buffer. As shown in Table 1, LVs adsorbed to both matrices. Nevertheless, $\mathrm{CIM}^{\circledR}$ DEAE presented higher recoveries in LVs elution, with a yield of $55 \pm 2 \%$. Since monolithic columns provided higher performance, best chromatographic buffers for elution were studied in this matrix to obtain optimal purification conditions. Efficient separation of viral particles and contaminant proteins was achieved using $0.65 \mathrm{M}$ of $\mathrm{NaCl}$ for elution (Fig. 2). After elution, volumes between 10 and $24 \mathrm{ml}$ were

Table 1. Infectious Titers, Concentration Factors, and Recoveries Obtained at the End of Each Downstream Process Step, Before and After Optimization

\begin{tabular}{|c|c|c|c|c|c|c|}
\hline & \multicolumn{3}{|c|}{ Before optimization } & \multicolumn{3}{|c|}{ After optimization } \\
\hline & Infectious titer $\left(x 10^{7} \mathrm{IP} / \mathrm{ml}\right)$ & $C F$ & Recovery (\%) & Infectious titer $\left(x 10^{7} \mathrm{IP} / \mathrm{ml}\right)$ & $C F$ & Recovery (\%) \\
\hline \multicolumn{7}{|l|}{ Clarification } \\
\hline Centrifugation & $0.24 \pm 0.01$ & - & $71 \pm 6$ & & & \\
\hline Depth-filtration & $0.25 \pm 0.01$ & - & $74 \pm 5$ & $0.30 \pm 0.02$ & - & $91 \pm 6^{\mathrm{a}}$ \\
\hline \multicolumn{7}{|l|}{ Purification (AEXc) } \\
\hline Sartobind D MA75 & $2.3 \pm 0.1$ & 12.5 & $28 \pm 4$ & & & \\
\hline CIM DEAE & $6.1 \pm 0.2$ & 27.1 & $55 \pm 2$ & $8.0 \pm 0.4$ & 21.7 & $80 \pm 5^{\mathrm{b}}$ \\
\hline \multicolumn{7}{|l|}{ Concentration (UF/DF) } \\
\hline \multirow{2}{*}{ Vivaspin } & $4.50 \pm 0.04$ & 3.4 & $67 \pm 6$ & & & \\
\hline & $4.5 \pm 0.2$ & 1.1 & $68 \pm 9$ & & & \\
\hline Vivaflow $\quad 100 \mathrm{KDa}$ & $4.8 \pm 0.1$ & 1.6 & $72 \pm 1$ & & & $72 \pm 1^{\mathrm{c}}$ \\
\hline Polishing (SEC) & $0.11 \pm 0.02$ & - & $27 \pm 2$ & $0.82 \pm 0.05$ & - & $68 \pm 7^{\mathrm{d}}$ \\
\hline Overall Recovery (\%) & & 8 & & & & $36^{\mathrm{e}}$ \\
\hline
\end{tabular}




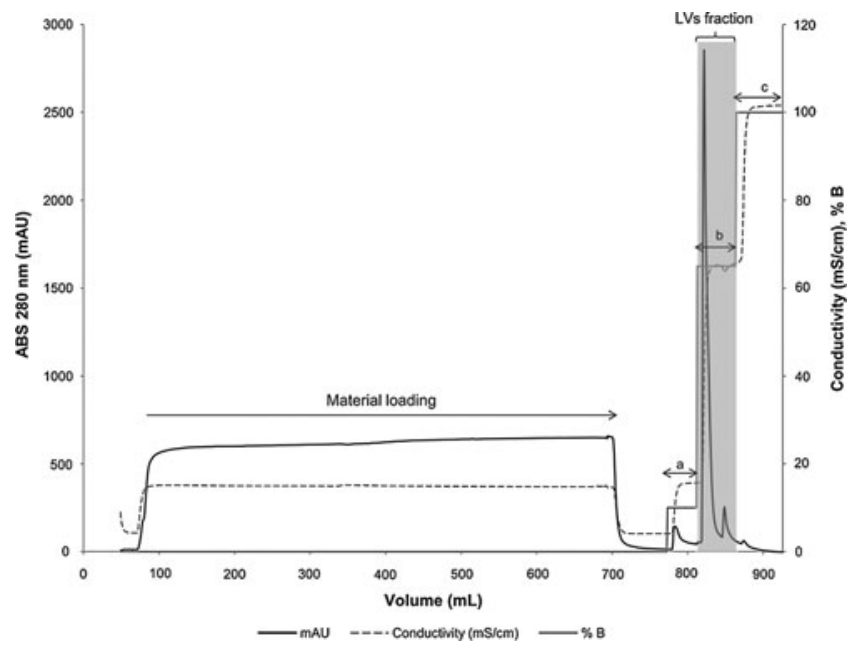

FIG. 2. Stepwise elution chromatographic profile obtained after loading the $\mathrm{CIM}^{\circledR}$ monolithic column with diethylaminoethanol (DEAE) anion exchangers with $560 \mathrm{ml}$ of clarified supernatant. Matrices were equilibrated with Tris- $\mathrm{HCl}$ buffer. Stepwise elution was performed using $10 \mathrm{mM}$ Tris buffer with $0.1 \mathrm{M} \mathrm{NaCl}$ (a) to release the weakly bonded proteins, $0.65 \mathrm{M}$ $\mathrm{NaCl}(\mathrm{b})$ for lentiviral vectors (LVs) elution (fraction identified in the gray box), and $1 \mathrm{M} \mathrm{NaCl}$ (c) to regenerate the column and to remove stronger bonded impurities. Loading and elution was performed at $10 \mathrm{ml} \mathrm{min}^{-1}$. Dashed line represents the conductivity in $\mathrm{mS} / \mathrm{cm}$, the bold line the absorbance at $280 \mathrm{~nm}$ (mAU), and the gray line the molarity in \% of buffer B (Tris- $\mathrm{HCl}$ with $1.0 \mathrm{M} \mathrm{NaCl}$, pH 8.0).

obtained. Given the potential detrimental effect of high salt concentrations on the infectivity of the viral particles, a fivefold dilution step of the LVs samples with Tris- $\mathrm{HCl}$ buffer (without $\mathrm{NaCl}$ ), immediately after elution, was included in our protocol. This dilution allowed the establishment of an optimal $\mathrm{pH}$ and low salt concentrations for the LVs samples, therefore achieving infectious titers of $8.0 \pm 0.4 \times 10^{7} \mathrm{IP} / \mathrm{ml}$. In contrast, aliquots from the same viral samples, which were not diluted after elution but instead were maintained in a $0.65 \mathrm{M} \mathrm{NaCl}$ buffer for $30 \mathrm{~min}$, showed infectious titers of $6.1 \pm 0.2 \times 10^{7} \mathrm{IP} / \mathrm{ml}$, a decrease of $24 \%$. The inclusion of this dilution step may explain the higher recoveries obtained, which increased the clarification step yield to $80 \pm 5 \%$ (Table 1).

An assay comparing the performance of three different chromatographic buffers (HEPES, PBS, and Tris) in the elution of the LVs revealed similar recoveries (between $71 \pm 4 \%$ and $80 \pm 5 \%$ ) (Table 2$)$ and high infectivity ranges $\left(>5.2 \times 10^{4}\right.$ $\mathrm{IP} / \mathrm{ng}$ p24) for all the buffers studied.

TABle 2. Impact of the Chromatographic Buffers UsEd For LV ELUTION (50 MM HEPES, 10 MM TRIS, AND PBS) IN THE INFEctious Titer, CONCENTRATION, AND STEPWISE Recovery

\begin{tabular}{lccc}
\hline & Infectious titer $\left(\times 10^{7} \mathrm{IP} / \mathrm{ml}\right)$ & CF & Recovery $(\%)$ \\
\hline HEPES & $7.1 \pm 0.4$ & 7.3 & $71 \pm 4$ \\
Tris & $8.0 \pm 0.4$ & 6.4 & $80 \pm 5$ \\
PBS & $7.4 \pm 0.4$ & 5.2 & $74 \pm 8$
\end{tabular}

The errors correspond to standard deviation $(n=3)$.
Concentration and polishing. After elution, the collected and diluted peak fraction was concentrated using UF/DF techniques. The main aim of this step was to concentrate the diluted viral peak to less than $5 \%$ (i.e., $16 \mathrm{ml}$ ) of total SEC column volume in order to guarantee a high resolution in the SEC step. Vivaspin (of 100 and $300 \mathrm{kDa}$ ) and Vivaflow systems (of $100 \mathrm{kDa}$ ) were used and compared, showing similar stepwise yields (from $67 \pm 6 \%$ to $72 \pm 1 \%$ ) (Table 1). Vivaflow cassettes, however, had to be saturated with HSA before concentration, since, without this coating, very low recoveries $(8.5 \pm 1.3 \%)$ were obtained (data not shown). All the systems used were equally efficient, with only $1.5 \pm 0.7 \%$ of total infectious viral particles being lost in the permeate.

The suitability of the Superdex XK26/60 column for size exclusion chromatography was analyzed for further purification and separation of LVs from remaining low molecular weight contaminants. This specific matrix excludes the viral particles from the matrix pores and separates proteins without excessive dilution of the vectors. Elution profiles were generated after injection of up to $16 \mathrm{ml}$ of viral sample at $2 \mathrm{ml} \mathrm{min}^{-1}$, using Tris buffer with $150 \mathrm{mM} \mathrm{NaCl}$ at $\mathrm{pH} 7.8$ (Fig. 3). The void volume of the column is equivalent to approximately $30 \%$ of the total column volume (i.e., $106 \mathrm{ml}$ ). Therefore, the LVs were eluted as one peak, starting at the column void volume, and indicating that the injected LVs were already highly pure. Stepwise recoveries of purified vectors after this step were in the range of $27 \pm 2 \%$ of the injected infectious particles $\left(0.40 \pm 0.05 \times 10^{7} \mathrm{IP} / \mathrm{ml}\right)$. However, after increasing the concentration (infectious titer) of the loading material by six-fold (to $2.4 \pm 0.2 \times 10^{7} \mathrm{IP} / \mathrm{ml}$ ), yields were enhanced up to $68 \pm 7 \%$ (Table 1 ).

Overall, recoveries of infectious particles of $36 \%$ were obtained for the purification protocol described herein after optimization of several parameters used in each step of the process.

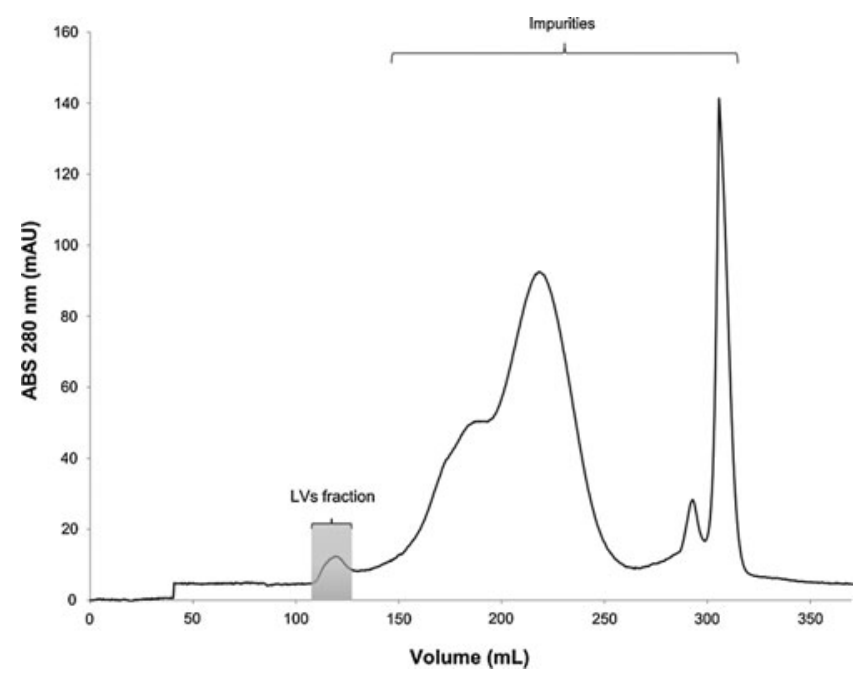

FIG. 3. Chromatographic profile of LVs by size-exclusion chromatography using a Superdex XK26/60 column. The viral sample was injected into the column and eluted at a flow rate of $2 \mathrm{ml} \mathrm{min}^{-1}$ using Tris buffer with $150 \mathrm{mM} \mathrm{NaCl}$, at $\mathrm{pH}$ 7.8. LVs were eluted as one peak (identified in the gray box), starting at the column void volume $(106 \mathrm{ml})$. 
Table 3. Effect of Benzonase Endonuclease Addition IN THE ReMOVAl of DNA IMPURITIES DURING the Downstream Process Herein Described

\begin{tabular}{|c|c|c|c|}
\hline DSP step & $\begin{array}{c}\text { No } \\
\text { Benzonase }\end{array}$ & $\begin{array}{l}\text { Before } \\
A E X c\end{array}$ & $\begin{array}{l}\text { After } \\
\text { AEXc }\end{array}$ \\
\hline Benzonase used $(50 \mathrm{U} / \mathrm{ml})$ & - & $28000 \mathrm{U}$ & $1000 \mathrm{U}$ \\
\hline $\begin{array}{l}\text { Clarification } \\
\text { Total } \mu \mathrm{g} \text { of DNA } \\
\mu \mathrm{g} \text { DNA } / 10^{8} \mathrm{IP}\end{array}$ & $\begin{array}{c}45 \pm 6 \\
3.8\end{array}$ & $\begin{array}{c}34 \pm 4 \\
2.0\end{array}$ & $\begin{array}{c}35 \pm 4 \\
3.2\end{array}$ \\
\hline $\begin{array}{l}\text { Purification } \\
\text { Total } \mu \mathrm{g} \text { of DNA } \\
\mu \mathrm{g} \text { DNA } / 10^{8} \mathrm{IP}\end{array}$ & $\begin{array}{c}5.03 \pm 0.01 \\
1.3\end{array}$ & $\begin{array}{c}1.0 \pm 0.2 \\
0.2\end{array}$ & $\begin{array}{c}0.91 \pm 0.06 \\
0.3\end{array}$ \\
\hline DNA removal (\%) & 88.8 & 97.1 & 97.4 \\
\hline $\begin{array}{l}\text { Concentration } \\
\text { Total } \mu \mathrm{g} \text { of DNA } \\
\mu \mathrm{g} \text { DNA } / 10^{8} \mathrm{IP}\end{array}$ & $\begin{array}{l}\text { ND } \\
\text { ND }\end{array}$ & $\begin{array}{c}0.8 \pm 0.2 \\
0.33\end{array}$ & $\begin{array}{c}0.010 \pm 0.001 \\
0.02\end{array}$ \\
\hline Overall DNA removal (\%) & ND & 97.7 & 99.9 \\
\hline
\end{tabular}

$50 \mathrm{U} / \mathrm{ml}$ of Benzonase was added after clarification and AEXc steps. Total DNA content of these samples was measured during the clarification, purification, and concentration steps by Quant-iT PicoGreen dsDNA Assay Kit. The errors correspond to standard deviation $(n=3)$.

$\mathrm{ND}$, data not determined.

\section{Characterization of purified lentiviral vectors}

LVs samples from several steps of the process were analyzed for infectious titer, infectivity, stability in the formulation, and for the presence of impurities. The LVs infectious titer from samples of the harvested bulk reached $1.1 \times 10^{7} \mathrm{IP} / \mathrm{ml}$. After performing the purification process herein described, ranges from $1.8 \times 10^{7} \mathrm{IP} / \mathrm{ml}$ (including the polishing step) to $4.7 \times 10^{7} \mathrm{IP} / \mathrm{ml}$ (without the polishing step) were obtained. The infectivity of the LVs samples showed to be high, reaching $7.3 \times 10^{4} \mathrm{IP} / \mathrm{ng}$ of $\mathrm{p} 24$.

Analysis of the LVs infectious titer after freeze-thawing revealed a drop to $84 \pm 3 \%$ (from $1.7 \pm 0.1$ to $0.28 \pm 0.01 \times 10^{7}$ $\mathrm{IP} / \mathrm{ml}$ ); however, samples stored in a formulation containing sucrose and HSA had a loss of only $26 \pm 2 \%$ of infectious particles (from $1.7 \pm 0.1$ to $1.3 \pm 0.1 \times 10^{7} \mathrm{IP} / \mathrm{ml}$ ) after freezethawing. The addition of these, or potentially other, stabilizers is, therefore, essential.

Analysis of DNA impurities showed that the amount of DNA present in the clarified supernatant ranged from 2 to $4 \mu \mathrm{g}$ per $10^{8} \mathrm{IP}$. Results revealed that the monolithic column, on its own, reduced the DNA content by $88.8 \%$ (Table 3 ). However, in order to further reduce the DNA, $50 \mathrm{U} / \mathrm{ml}$ of Benzonase was added either to the clarified supernatant or after the AEXc step. Samples treated with Benzonase before injection in AEXc presented DNA removal efficiencies of $97.7 \%$; samples treated with Benzonase after AEXc showed even higher DNA removal efficiencies (99.9\%). Final LV samples had DNA impurities below $0.02 \mu \mathrm{g}$ per $10^{8} \mathrm{IP}$ (Table 3 ).

\section{Discussion}

The establishment of a downstream process for virus purification involves the combination and optimization of several steps and parameters toward maximum infectious particle titers and final maximal recoveries. For the specific case of LVs, the challenge is to achieve clinical grade preparations with high titer and high quality in a short period of processing time, since these vectors are very unstable, rapidly losing infectivity.

In the present study, a multistep protocol was developed, combining several chromatographic and membrane-based process techniques (Fig. 1) that had been reported in the literature as promising for the purification of retroviral and lentiviral vectors. CIM DEAE monolithic columns were used for the first time by Lesch et al. (2011) to remove LVs from a baculoviral vectors' bulk, achieving stepwise yields of $65 \%$. Due to the high recoveries obtained, these matrices were used herein and each step of the process was improved to allow higher yields and purer viral preparations.

In the clarification step, recoveries of $91 \%$ were obtained using the depth-filter capsules. These results, in accordance with the literature (Segura et al., 2005),were obtained after optimizing the flow rate from 50 to $100 \mathrm{ml} \mathrm{min}^{-1}$. The use of these higher flow rates promoted a lower entrapment of the viruses in the filter pores, which may explain the higher recoveries obtained. Depth-filter capsules are disposable, scalable and easy for good manufacturing practice (GMP) validation and were, therefore, the clarification method of choice for the downstream process herein described. This step could be further optimized depending on the LVs envelope used, which may affect viral stability and vector affinity to the membrane. Moreover, a broad range of sizes (up to $0.45 \mathrm{~m}^{2}$ ) and formats of filter elements are available, allowing a scale-up of this step.

Fast processing and a reduced number of downstream processing steps are required for minimization of vector losses. It was already known that fixed-bed AEXc (with DEAE adsorbers) offered one of the best binding and elution conditions for RVs and LVs purification (Rodrigues et al., 2006; Lesch et al., 2011). Therefore, AEXc efficiency in LVs purification was herein analyzed using CIM monolithic columns. High stepwise yields of $80 \%$ were obtained, an improvement of $10 \%$ over the currently reported state-of-the-art values (Slepushkin et al., 2003). The use of different chromatographic buffers for viral elution showed yields in the range of $70 \%$. However, in order to avoid any $\mathrm{pH}$ limitations for virus binding to the AEXc matrices and due to PBS lack of buffering capacity at lower temperatures and its incompatibility with the Benzonase step (Eglon et al., 2009) Tris was the buffer chosen for elution. CIM DEAE has advantages over other chromatographic matrices, namely convective mass transport, extremely fast separations, high-resolution power, and high binding capacities for viruses (Jungbauer and Hahn, 2008; Gagnon, 2010) and permitted: i) an improved preservation of viral infectivity during purification; ii) an increase of the step yields, and iii) a reduction in processing time, from five working days when using gradient centrifugation protocols to $3 \mathrm{hr}$.

Vivaspin and Vivaflow systems were used to concentrate the LVs after AEXc. Both systems showed similar recoveries. However, since Vivaspin's scalability is limited by the size of the centrifuge and is much more time-consuming, Vivaflow was the preferred system because of its higher scalability and ability to perform diafiltration. To assure high resolution in the next step (SEC), only up to $5 \%$ (i.e., $16 \mathrm{ml}$ ) of the total SEC column volume should be injected. Therefore, the LVs fractions (from 10 to $24 \mathrm{ml}$ in volume), previously diluted five- 


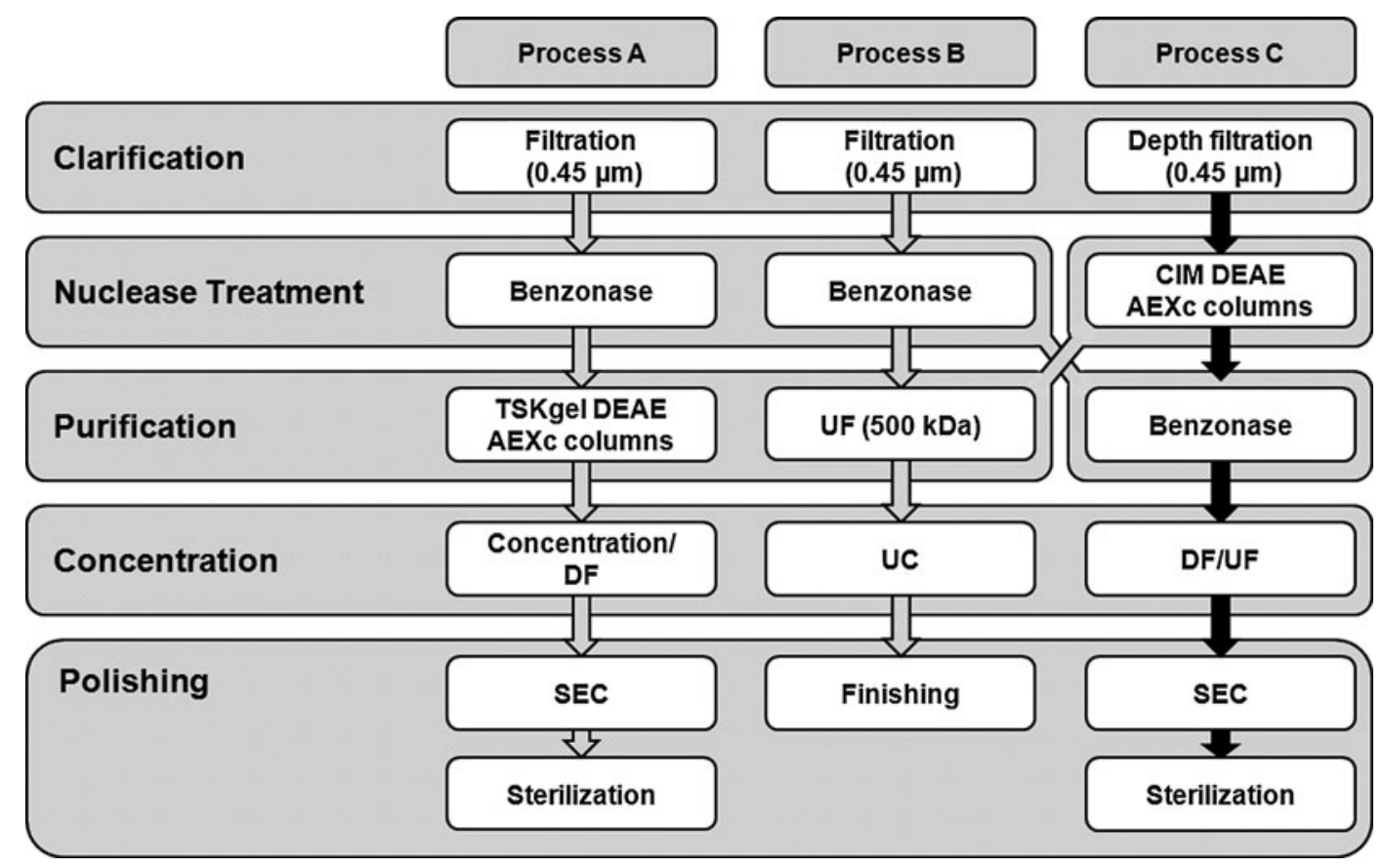

FIG. 4. Downstream process developed in this work (Process C), compared with two representative downstream strategies to purify vesicular stomatitis virus envelope glycoprotein (VSV-g) pseudotyped LVs from Genéthon (Merten et al., 2011; Process A) and Beckman (Couture, 2008; Process B). UC, ultracentrifugation. (Adapted from Schweizer and Merten, 2010).

fold to avoid infectivity losses, were concentrated by UF/DF to $7-13 \mathrm{ml}$, resulting in concentration factors between 1.1 and 3.4-fold. For a better analysis, larger production and purification scales would be required. Hollow-fibers or flat-sheet cassettes can be used for large-scale processes, without the need for pre-coating, and recoveries of $100 \%$, with concentration factors of 20 to 66-fold, and have already been reported for both RVs (Rodrigues et al., 2007b) and LVs (Geraerts et al., 2005). However, disposable cartridges such as MidGee (of 500 and $750 \mathrm{kDa}$ MWCO) only permit processing of volumes from 25 to $200 \mathrm{ml}$.

The presence of residual DNA in the final viral preparations, derived from host producer cells and plasmid contamination (Chen et al., 2001), should be reduced in their amount and size to below approximately 200 base pairs in order to avoid the transfer of a residual functional open reading frame (FDA Guidance for Industry, 2010) and to further increase the product's purity. DNAses, such as Benzonase endonuclease, are often used to decrease the DNA load (Sastry et al., 2004) and to reduce the length of oligonucleotide fragments down to 3-8 bp (Janning et al, 1994). In this work, purified and nonpurified samples (after and before AEXc, respectively) were incubated with $50 \mathrm{U} / \mathrm{ml}$ of Benzonase for $30 \mathrm{~min}$ at $37^{\circ} \mathrm{C}$. Although an early Benzonase addition reduces large DNA pieces in size, facilitating their elimination during the following purification steps, higher DNA removals $(99 \%)$ were obtained for Benzonase addition after the AEXc step $\left(0.02 \mu \mathrm{g}\right.$ per $\left.10^{8} \mathrm{IP}\right)$. This result is comparable to those already described by Merten et al. (2011) for GMP runs but reflect a much less expensive approach, since 28 times less Benzonase was used.

Sterile filtration at $0.22 \mu \mathrm{m}$ was performed as a final purification step, although it is known for being responsible for vector infectivity losses. In this step, losses lower than $30 \%$ were observed; however, this could not be avoided because no alternative sterilization method was available. The implementation of a semi-closed system that would allow it to perform all the purification steps in a sterile environment would make this sterile filtration step unnecessary.

In summary, the best DSP approach obtained in this study (Process C) integrates filtration and chromatographic techniques, being closely related to other processes recently described for LVs purification, such as the ones published by Merten et al. (2011) (Process A) and Couture (2008) (Process B) (Fig. 4). In Process C, CIM ${ }^{\circledR}$ DEAE monolithic columns improved the purification step yields to $80 \%, 42 \%$ more than the results obtained by Merten et al. (2011) (Process A) and Zimmermann et al. (2011) (using TSKgel DEAE columns and LentiSelect kits, respectively) and 10\% more than obtained by Slepushkin et al. (2003) using Mustang Q Ion Exchange Capsules. Furthermore, a faster process was achieved, with overall infectious vector recoveries of $36 \%, 12 \%$ more than obtained in Process A. Similar yields have only been obtained, until now, in Process B or by Dupont (2008); however, fewer purification steps were used in the former one, which may justify the higher yields obtained.

The work hereby presented compared several purification methods and established a novel downstream process strategy for the purification of LVs. The use of $\mathrm{CIM}^{\circledR}$ monoliths for LVs elution allowed the achievement of a faster, more efficient, and enhanced purification protocol. Progress in downstream processing will contribute to improve LVs purification toward clinical-scale for gene therapy trials and, hopefully later, for industrial-scale. Additionally, by providing higher quality grade preparations and, thus, increased safety to patients, it will contribute to faster advances in the gene therapy field. 


\section{Acknowledgments}

The authors would like to acknowledge Sartorius Stedim Biotech and BIA Separations for their technical advice and for providing chromatographic matrices. Financial support received from European Commission Clinigene Network of Excellence (LSHB-CT-2006) and Fundação para a Ciência e Tecnologia-Portugal (PTDC/EBB-BIO/100491/2008, PTDC/ EBB-BIO/102649/2008 and SFRH/BD/48393/ 2008).

\section{Author Disclosure Statement}

No competing financial interests exist.

\section{References}

Baekelandt, V., Eggermont, K., Michiels, M., et al. (2003). Optimized lentiviral vector production and purification procedure prevents immune response after transduction of mouse brain. Gene. Ther. 10, 1933-1940.

Barut, M., Podgornik, A., Brne, P., et al. (2005). Convective interaction media short monolithic columns: enabling chromatographic supports for the separation and purification of large biomolecules. J. Sep. Sci. 28, 1876-1892.

Beer, C., Meyer, A., Muller, K., et al. (2003). The temperature stability of mouse retroviruses depends on the cholesterol levels of viral lipid shell and cellular plasma membrane. Virology 308, 137-146.

Carmo, M., Faria, T.Q., Falk, H., et al. (2006). Relationship between retroviral vector membrane and vector stability. J. Gen. Virol. 87, 1349-1356.

Carmo, M., Panet, A., Carrondo, M.J., et al. (2008). From retroviral vector production to gene transfer: spontaneous inactivation is caused by loss of reverse transcription capacity. J. Gene Med. 10, 383-391.

Carmo, M., Dias, J.D., Panet, A., et al. (2009). Thermosensitivity of the reverse transcription process as an inactivation mechanism of lentiviral vectors. Hum. Gene Ther. 20, 1168-1176.

Chen, J., Reeves, L., Sanburn, N., et al. (2001). Packaging cell line DNA contamination of vector supernatants: implication for laboratory and clinical research. Virology 282, 186-197.

Coroadinha, A.S., Ribeiro, J., Roldão, A., et al. (2006a). Effect of medium sugar source on the production of retroviral vectors for gene therapy. Biotechnol. Bioeng. 94, 24-36.

Coroadinha, A.S., Silva, A.C., Pires, E., et al. (2006b). Effect of osmotic pressure on the production of retroviral vectors: Enhancement in vector stability. Biotechnol. Bioeng 94, 322329.

Couture, L. (2008). Vector production in support of early clinical trials. Presented at the $11^{\text {th }}$ annual ASGT Meeting, Boston.

Dupont, F. (2008). Large scale manufacturing of a lentiviral vector (ProSavin $\left.{ }^{\circledR}\right)$ for phase I/II clinical trial. Presented at the CONSERT Labcourse, Evry, France.

Eglon, M.N., Duffy, A.M., O’Brien, T., et al. (2009). Purification of adenoviral vectors by combined anion exchange and gel filtration chromatography. J. Gene Med. 11, 978-989.

Food and Drug Administration (2010). Guidance for Industry Characterization and Qualification of Cell Substrates and Other Biological Materials Used in the Production of Viral Vaccines for Infectious Disease Indications. Available at www.fda.gov/downloads/biologicsbloodvaccines/guidance complianceregulatoryinformation/guidances/vaccines/ucm 202439.pdf (accessed April 2012).

Gagnon, P. (2010). Monoliths open the door to key growth sectors. BioProcess International 8, 20-23.
Gene Therapy Clinical Trials (2012). Available at www.wiley .co.uk/genmed/clinical (accessed June 2012).

Geraerts, M., Michiels, M., Baekelandt, V., et al. (2005). Upscaling of lentiviral vector production by tangential flow filtration. J. Gene Med. 7, 1299-1310.

Higashikawa, F., and Chang, L. (2001). Kinetic analyses of stability of simple and complex retroviral vectors. Virology 280, 124-131.

Ikeda, Y., Takeuchi, Y., Martin, F., et al. (2003). Continuous high-titer HIV-1 vector production. Nat. Biotechnol. 21, 569-572.

Janning, P., Schrader, W., and Linscheid, M. (1994). A new mass spectrometric approach to detect modifications in DNA. Rapid Commun. Mass Spectrom. 8, 1035-1040.

Jungbauer, A., and Hahn, R. (2008). Polymethacrylate monoliths for preparative and industrial separation of biomolecular assemblies. J. Chromatogr. A 1184, 62-79.

Lesch, H.P., Laitinen, A., Peixoto, C., et al. (2011) Production and purification of lentiviral vectors generated in $293 \mathrm{~T}$ suspension cells with baculoviral vectors. Gene Ther. 18, 531-538.

Merten, O.W., Charrier, S., Laroudie, N., et al. (2011). Large-scale manufacture and characterization of a lentiviral vector produced for clinical ex vivo gene therapy application. Hum. Gene Ther. 22, 343-356.

Morenweiser, R. (2005). Downstream processing of viral vectors and vaccines. Gene Ther. 12, S103-S110.

Naldini, L., Blomer, U., Gage, F.H., et al. (1996a). Efficient transfer, integration, and sustained long-term expression of the transgene in adult rat brains injected with a lentiviral vector. Proc. Natl. Acad. Sci. U.S.A. 93, 11382-11388.

Naldini, L., Blomer, U., Gallay, P., et al. (1996b). In vivo gene delivery and stable transduction of nondividing cells by a lentiviral vector. Science 272, 263-267.

Podgornik, A., and Štrancar, A. (2005). Convective Interaction Media ${ }^{\circledR}(\mathrm{CIM})$ - short layer monolithic chromatographic stationary phases. Biotechnol. Annu. Rev., 281-333.

Reeves, L., and Cornetta, K. (2000). Clinical retroviral vector production: step filtration using clinically approved filters improves titers. Gene Ther. 7, 1993-1998.

Rodrigues, T., Carvalho, A., Roldao, A., et al. (2006). Screening anion-exchange chromatographic matrices for isolation of onco-retroviral vectors. J. Chromatogr. B. Analyt. Technol. Biomed. Life Sci. 837, 59-68.

Rodrigues, T., Carrondo, M.J., Alves, P.M., et al. (2007a). Purification of retroviral vectors for clinical application: biological implications and technological challenges. J. Biotechnol. 127, 520-541.

Rodrigues, T., Carvalho, A., Carmo, M., et al. (2007b). Scaleable purification process for gene therapy retroviral vectors. J. Gene Med. 9, 233-243.

Sastry, L., Xu, Y., Cooper, R., et al. (2004). Evaluation of plasmid DNA removal from lentiviral vectors by Benzonase treatment. Hum. Gene Ther. 15, 221-226.

Schambach, A., and Baum, C. (2008). Clinical application of lentiviral vectors - concepts and practice. Curr. Gene Ther. 8, 474-482.

Schweizer, M., and Merten, O.W. (2010). Large-scale production means for the manufacturing of lentiviral vectors. Curr. Gene Ther. 10, 474-486.

Segura, M.M., Kamen, A., Trudel, P., et al. (2005). A novel purification strategy for retrovirus gene therapy vectors using heparin affinity chromatography. Biotech. Bioeng. 90, 391-404. 
Segura, M.M., Kamen, A., and Garnier, A. (2006). Downstream processing of oncoretroviral and lentiviral gene therapy vectors. Biotechnol. Adv. 24, 321-337.

Slepushkin, V., Chang, N., Cohen, R., et al. (2003). Large-scale purification of a lentiviral vector by size exclusion chromatography or Mustang Q ion exchange capsule. BioProcess. J. 2, 89-95.

Transfiguracion, J., Jaalouk, D.E., Ghani, K., et al. (2003). Sizeexclusion chromatography purification of high-titer vesicular stomatitis virus $G$ glycoprotein-pseudotyped retrovectors for cell and gene therapy applications. Hum. Gene Ther. 14, 1139-1153.

Xu, K., Ma, H., Mccown, T.J., et al. (2001). Generation of a stable cell line producing high-titer self-inactivating lentiviral vectors. Mol. Ther. 3, 97-104.

Zimmermann, K., Scheibe, O., Kocourek, A., et al. (2011). Highly efficient concentration of lenti- and retroviral vector prepara- tions by membrane adsorbers and ultrafiltration. BMC Biotechnology 11, 55.

Address correspondence to:

Prof. Manuel J. T. Carrondo

Instituto de Biologia Experimental e Tecnológica

Apartado 12

2781-901 Oeiras

Portugal

E-mail: mjtc@itqb.unl.pt

Received for publication March 17, 2012;

accepted after revision July 27, 2012.

Published online: July 30, 2012. 